\title{
Nanotechnological Approach to the Treatment of Diabetes
}

\author{
Araceli Ramirez ${ }^{1, *}$, Griselda Corro ${ }^{1}$, Alfred Zehe ${ }^{1}$, Andreas Thomas ${ }^{2}$ \\ ${ }^{1}$ Benemérita Universidad Autónoma de Puebla, Centro de Nanotecnología, Ciudad Universitaria, 72550 Puebla, México \\ ${ }^{2}$ Medtronic GmbH, Earl-Bakken-Platz 1, D-40670 Meerbusch, Germany \\ *Corresponding author: nanotron2012@gmail.com
}

\begin{abstract}
Nanotechnology in diabetes research has facilitated the evolution of novel glucose measurement and insulin delivery systems. As type 1 diabetes mellitus needs treatment with insulin from the very beginning on, the objective of any kind of diabetes therapy is to reach nearly physiological glucose levels. The current view points toward a continuous insulin infusion by means of an insulin pump. It is desirable then, that a glucose sensor would automatically control the insulin supply, given that an insulin pump works only manually. Worldwide diabetes research activities at its interface with nanotechnology have created devices at the micro- or nanoscale by which the experimental approach toward an artificial pancreas is already put in practice. The article discusses some aspects of conventional glucose sensors, as well as basic concepts and developments in the field of nanotechnology and their application in the field of diabetes research. Some types of nanoscale sensors and functionalized nanostructures as insulin-delivery systems are looked at, that could act as an artificial pancreas.
\end{abstract}

Keywords: artificial pancreas, diabetes mellitus, insulin, nanomaterials, nanoscale sensors

Cite This Article: Araceli Ramirez, Griselda Corro, Alfred Zehe, and Andreas Thomas, "Nanotechnological Approach to the Treatment of Diabetes.” American Journal of Medical Sciences and Medicine, vol. 6, no. 2 (2018):19-26. doi: 10.12691/ajmsm-6-2-1.

\section{Introduction}

Diabetes mellitus is a metabolic disease in which the body either fails to produce or fails to respond to the glucose regulatory hormone insulin characterized by chronically elevated blood glucose levels (BGL's) and an inability to maintain BGL homeostasis $[1,2,3]$. Insulin is required in order for cells to take up glucose from the blood, and in diabetics, a defect in insulin signaling can give rise to large fluctuations in blood glucose levels unless proper management techniques are employed.

Glucose itself is the most important energy source for the body's cells. Disruptions in this energy loop therefore represent a serious disease. Type 2 diabetes is characterized by the fact that insulin resistance and beta cell dysfunction is caused by various pathological factors, so that the glucose level can no longer be controlled in the desired glucose range. Diabetes has grown to become one of the largest public health challenges globally, affecting close to 400 million individuals worldwide. Therefore, systems which improve blood glucose monitoring and efficient treatment are highly desirable.

Worldwide research activities are under way in order to develop insulin-delivery systems that could act as an artificial pancreas, automatically detecting glucose levels and secreting insulin. Hereby nanotechnology is playing a pivotal role and carries the promise of attractive and viable solutions.

Yet, it cannot clearly be foreseen whether technical solutions in the sense of an artificial pancreas, or biological solutions by growing insulin-producing cells will be a valid answer. Both are technologically connected with principles and methods of nanotechnology. In the first case would result a technical product, in the second case biological material. Notable progress is made in both directions. To mention only few: An optical nanosensor, based on single walled nanotubes has been used as glucose sensor. It modulates fluorescence emission in response to the adsorption of specific biomolecules [4]. Nanotube transistors have been explored as glucose sensors [5], polymer encapsulation devices were presented to treat diabetes by thin-film micro- and nanoporous cell-encapsulation devices [6], magnetic nanoemulsion is studied for non-enzymatic blood glucose detection, whereby optical properties and intermolecular interactions in magnetically responsive nanoemulsions in the presence of glucose are probed [7], the development of a plasmonic gold chip for near-infrared fluorescence-enhanced detection of islet cell-targeting autoantibodies with high sensitivity and specificity for the diagnosis of type1 diabetes has been described in [8], biosensors are implanted for continuous glucose monitoring [9], grapheneoxide-multiwall carbon nanotube nanocomposites were fabricated as electrochemical platform for direct electrochemistry and electrocatalysis measurements[10], glucose-sensitive nanofiber scaffolds have recently been improved [11], photoluminescent enzymatic nanosensors for glucose sensing were prepared [12]. A bihormonal closed-loop artificial pancreas for type 1 diabetes was described [13], and an overview is given of stem cells, the purpose of nanotechnology and various surface 
modifications of nanoparticles for enhanced drug delivery, as well as of how stem cell therapy is used to treat type 1 and type 2 diabetes mellitus [14].

\section{Conventional Sensor Principle for Continuous Glucose Measurement}

The current standard of care for type 1 and advanced type 2 diabetics involves daily subcutaneous insulin injections. The best way of diabetes therapy is the continuous insulin infusion with the help of an insulin pump $[15,16,17,18]$. However, as an insulin pump works only manually, it is desirable, that a glucose sensor would automatically control the insulin supply.

\subsection{Electrochemical Glucose Measurement}

A common mechanism of glucose detection involves using hydrogen peroxide $\left(\mathrm{H}_{2} \mathrm{O}_{2}\right)$ or a similar reduced species as a chemical intermediary which drives the reduction of another species.

Advantages of hydrogen peroxide-based detection systems include relatively straightforward sensor operation and characterization via amperometric techniques [19,20], but fluorescence measurements have also proven useful [21].

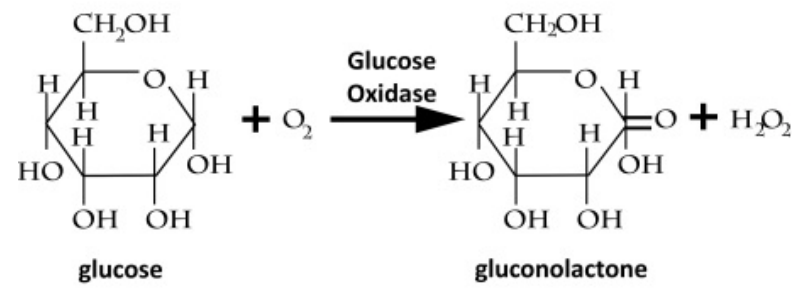

Figure 1. The oxidation of glucose by glucose oxidase. Glucose and diatomic oxygen are consumed to form a gluconolactone and hydrogen peroxide

Glucose oxidase (GOD) is capable of enzymatically catalyzing the oxidation of glucose to gluconic acid with high specificity (Figure 1):

$$
\begin{gathered}
\text { Glucose }+\mathrm{O}_{2}+\mathrm{H}_{2} \mathrm{O} \rightarrow \text { Gluconic acid }+\mathrm{H}_{2} \mathrm{O}_{2} \\
\mathrm{H}_{2} \mathrm{O}_{2} \rightarrow 2 \mathrm{H}^{+}+\mathrm{O}_{2}+2 \mathrm{e}^{-}
\end{gathered}
$$

From the reaction products formed during the GOD reaction, hydrogen peroxide $\left(\mathrm{H}_{2} \mathrm{O}_{2}\right)$ is oxidized electrochemically in a second reaction downstream at a platinum electrode with a voltage of $600 \ldots 900 \mathrm{mV}$. The resulting electrons generate a current flow, which is directly proportional to the amount of converted glucose (Figure 2).

At glucose concentrations of 40-400 mg/dl (2.2 to 22.2 $\mathrm{mmol} / \mathrm{l}$ ) such a current is typical in the nano-ampere range.

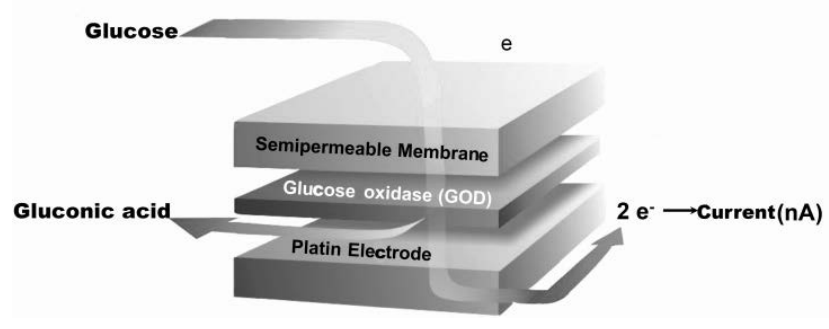

Figure 2. Schematic representation of an enzymatic glucose sensor

The electrochemical measurement requires direct access to the glucose-containing unit. This implies that the glucose sensor (the electrochemical enzyme electrode wrapped with an oxygen permeable membrane) has to be inserted through the skin into the subcutaneous adipose tissue in order to obtain access to interstitial fluid. Yet, only in the case of glucose stability would the glucose sensor measure the same glucose concentration as present in the blood. In the case of a glucose increase or decrease, a temporal shift from 5 to 25 minutes between the measured values in the blood and the interstitium will happen. Consequently, the importance of measured data is of little use unless the postponement in time is observed. Algorithms for the control of the insulin delivery in an artificial pancreas consider this fact, which not only realize the insulin delivery based on the existing glucose value, but also predict the glucose concentration over the subsequent period of 2-3 hours. It must be ensured that in addition to the glucose concentration $C_{G l u c}$ the insulin concentration $C_{I N S}$ is regulated in accordance to physiology. In principle, the glucose homeostasis is maintained through a system of networked negative-feedback loops. Beta cells and alpha cells represent the controller, and the secreted insulin or glucagon denote the manipulated variables. The latter should adjust the controlled variable "glucose" at a set point (3.9 to $7.8 \mathrm{mmol} / \mathrm{l}$ ) which ideally is situated between $70-140 \mathrm{mg} / \mathrm{dl}$. All of the processes within the controlled system operate with a time lag, as different factors enter the glycemic regulation, being it the time-dependent absorption of carbohydrates and insulin, physical activity, stress, etcetera (Figure 3).

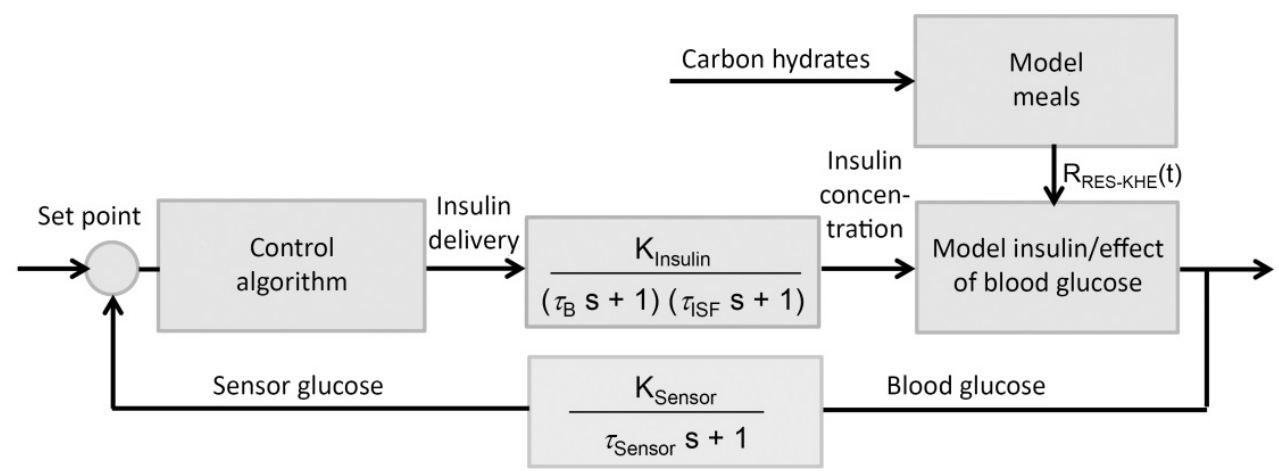

Figure 3. Control circuit for an AP considering a subcutaneous glucose monitoring and subcutaneous insulin dose ( $\mathrm{R}_{\mathrm{RES}-\mathrm{KHE}}$ - absorption of carbohydrates) 
The physiological insulin secretion can be simulated as $P I D$ control, where $P$ is the proportional control, $I$ the integral control, and $D$ represents the differential control $[22,23]$. These three phases correspond to the feedback behavior of the beta cells (Figure 3 ):

Proportional phase $(P)$ : This takes into account the difference between the current value of the glucose and the glucose target value $\left(\mathrm{C}_{\text {Sensor }}-\mathrm{C}_{\text {Target }}\right)$; the insulin delivery is proportional to the glucose levels

$$
\mathrm{P}(\mathrm{t})=\mathrm{K}_{\mathrm{p}} \mathrm{x}\left[\mathrm{C}_{\text {Sensor }}-\mathrm{C}_{\text {Target }}\right]
$$

$\mathrm{t}$ - time

$\mathrm{C}_{\text {Sensor }}$ - glucose concentration sensor

$\mathrm{C}_{\text {Target }}$ - target value of glucose concentration.

Escalation phase (Increment phase I): This is proportional to the difference between the current value of the glucose and the glucose target value $\left(\mathrm{C}_{\text {Sensor }}-\mathrm{C}_{\text {target }}\right)$

$$
\mathrm{dI}(\mathrm{t}) / \mathrm{dt}=\mathrm{K}_{\mathrm{p}} \mathrm{x}\left[\mathrm{C}_{\text {Sensor }}-\mathrm{C}_{\text {Target }}\right] / \mathrm{T}_{\mathrm{I}} .
$$

Response phase (phase Derivative): The insulin delivery is proportional to the rate of glucose change (D)

$$
\mathrm{D}(\mathrm{t})=\mathrm{K}_{\mathrm{p}} \mathrm{xT}_{\mathrm{D}} \mathrm{x} \mathrm{dC}(\mathrm{t}) / \mathrm{dt}
$$

$\mathrm{dC} / \mathrm{dt}$ - change of glucose concentration/time.

The parameter $K_{p}, T_{I}, T_{D}$ have to be adapted. The parameter $\mathrm{K}_{\mathrm{p}}$ (in $\mathrm{mIU} / \mathrm{min} / \mathrm{mg} / \mathrm{dl}$, IE -Insulin unit) determines the insulin secretion rate as response to the basal glucose levels, the parameter $T_{I}$ (in minutes) determines the proportion of the growth phase, and the parameter $T_{D}$ the proportion of the derivatives phase.

The total control algorithm results then as the sum of three components:

$$
\mathrm{PID}(\mathrm{t})=\mathrm{P}(\mathrm{t})+\mathrm{I}(\mathrm{t})+\mathrm{D}(\mathrm{t}) \text {. }
$$

Thus, the necessary insulin dosage is calculated from the knowledge of the current glucose concentration, the glucose target value and the parameters $K_{p}, T_{I}, T_{D}$. When the glucose sensor is placed subcutaneously and the glucose concentration is variable, the measured value of the glucose concentration $\mathrm{C}_{\mathrm{ISF}}$ (ISF - interstitial flow) is different from the blood glucose concentration $C_{B}$
(B - blood). This is shown in a simple continuity model (Figure 4).

The change in time of the glucose concentration in subcutaneous tissue depends on the glucose transfer between blood and interstitial fluid, represented by the flow rates of glucose $\mathrm{k}_{\mathrm{B}_{\rightarrow} \text { ISF, }}, \mathrm{k}_{\mathrm{ISF}_{\rightarrow} \mathrm{B}}$ and the flow of the glucose in the body cells $\mathrm{k}_{\mathrm{ISF}_{\rightarrow} \mathrm{z}}$ (glucose consumption). This is nicely reproduced in the time trail of spectra seen in Figure 4. An increase in the insulin concentration increases glucose consumption of the peripheral cells. The result is:

$$
\begin{aligned}
\mathrm{dC}_{\mathrm{ISF}} / \mathrm{dt}= & -\left(\mathrm{k}_{\mathrm{ISF} \rightarrow \mathrm{Z}}+\mathrm{k}_{\mathrm{B} \rightarrow \mathrm{ISF}}\right) \mathrm{xC}_{\mathrm{ISF}} \\
& +\mathrm{k}_{\mathrm{ISF} \rightarrow \mathrm{B}} \mathrm{xV}_{\mathrm{B}} / \mathrm{V}_{\mathrm{ISF}} \mathrm{XC}_{\mathrm{B}}
\end{aligned}
$$

$C_{B}$ - glucose concentration in the blood

$\mathrm{C}_{\mathrm{ISF}}$ - glucose concentration in interstitial

$\mathrm{V}_{\mathrm{B}}$ - volume in the blood

$\mathrm{V}_{\text {ISF }}$ - volume in the interstitium

$\mathrm{k}_{\mathrm{ISF} \rightarrow \mathrm{Z}}$ - glucose consumption in peripheral cells

$\mathrm{k}_{\mathrm{B} \rightarrow \mathrm{ISF}}$ - flow rate of blood $\rightarrow$ interstitial

$\mathrm{k}_{\mathrm{ISF} \rightarrow \mathrm{B}}$ - flow rate interstitial $\rightarrow$ blood.

The concentrations ratio of glucose in the interstitial flow and in the blood is $\left(\mathrm{C}_{\mathrm{ISF}} / \mathrm{C}_{\mathrm{B}}\right)$ the concentration gradient. After reaching the glucose homeostasis, the glucose concentration in the interstitial space is given by:

$\mathrm{C}_{\mathrm{ISF}}=\mathrm{C}_{\mathrm{B}} \mathrm{x}\left[\mathrm{k}_{\mathrm{ISF} \rightarrow \mathrm{B}} \mathrm{X} \mathrm{V}_{\mathrm{B}} / \mathrm{V}_{\mathrm{ISF}}\right] /\left(\mathrm{k}_{\mathrm{ISF} \rightarrow \mathrm{Z}}+\mathrm{k}_{\mathrm{B} \rightarrow \mathrm{ISF}}\right)$. (8)

The time delay of the glucose concentration in the interstitial space compared to the blood ('time-lag') is:

$$
\tau_{\text {Sensor }}=\left(\mathrm{k}_{\mathrm{B} \rightarrow \mathrm{ISF}}+\mathrm{k}_{\mathrm{ISF} \rightarrow \mathrm{Z}}\right)^{-1} .
$$

This time constant refers to the time needed to reach a $63 \%$ of the balance.

When using an enzymatic electrochemical glucose sensor, a sensor current is created in the interstitial space proportional to the glucose concentration $\mathrm{I}_{\mathrm{sig}}$ :

$$
\mathrm{I}_{\text {sig }}=\alpha \mathrm{xC}_{\mathrm{ISF}}
$$

It is $\alpha$ a parameter expressing the sensitivity of the sensor (in $\mathrm{nA} / \mathrm{mg} / \mathrm{dl}$ ). This is not a constant in time during the entire application.
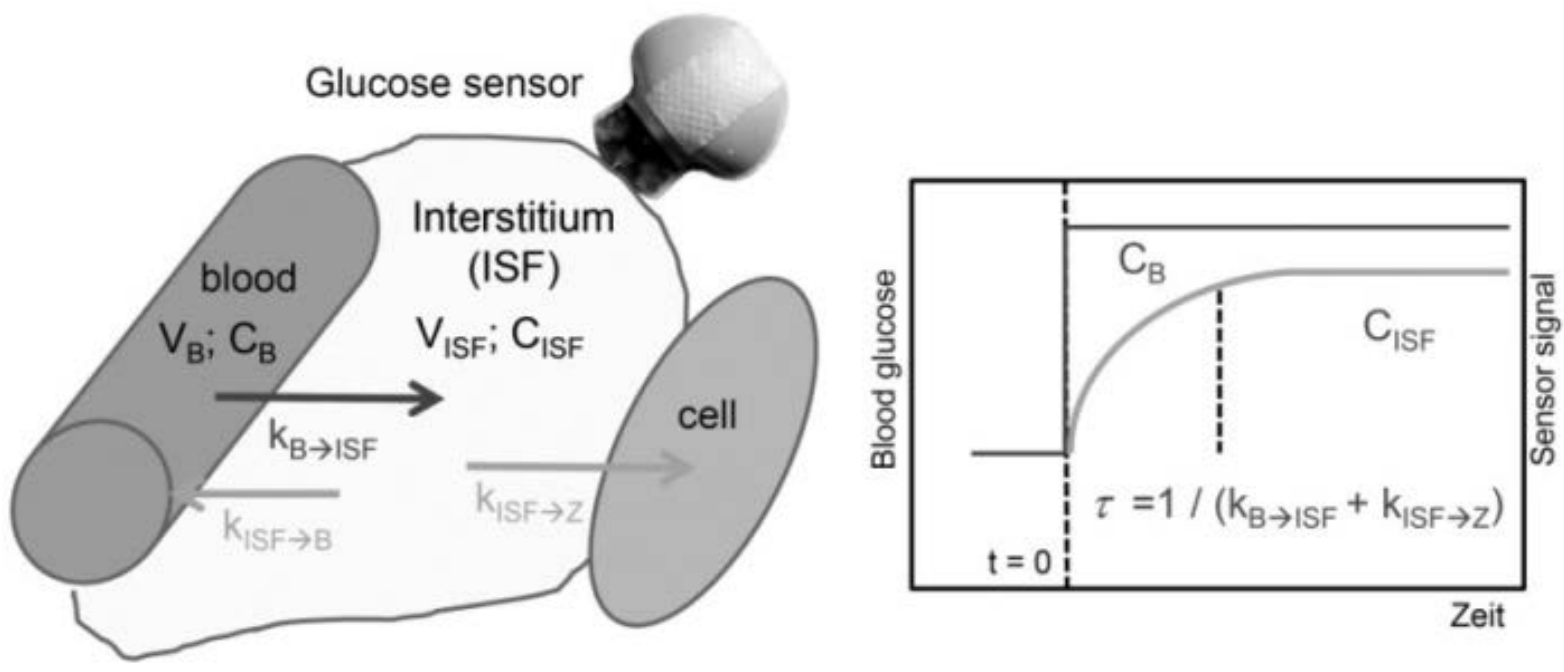

Figure 4. Model for glucose exchange between blood and interstitial (right: reaction of the sensor signal to a change in blood glucose) 
Because the glucose sensor must be calibrated, the measured glucose concentration with the calibration factor $\mathrm{F}_{\text {cal }}$ gives finally:

$$
\mathrm{C}_{\text {Sensor glucose }}=\mathrm{F}_{\text {cal }} \mathrm{XI}_{\text {sig }} \text {. }
$$

In the PID model follows the necessary insulin dosage per unit time as

$$
\mathrm{I}_{\text {Dosis }}=\mathrm{K}_{\mathrm{p}} \mathrm{x} \mathrm{F}_{\text {Err }}+1 / \mathrm{T}_{\mathrm{I}} \int \mathrm{F}_{\mathrm{Err}} \mathrm{xdt}+\mathrm{TD}_{\mathrm{s}}
$$

$F_{E r r}$ is the resulting error due to a deviation of the blood glucose, $K_{p}, T_{I}, T_{D}$ are individually tailored parameters from the PID model.

Eq. 12 does not take into account that insulin delivery is subcutaneous. In that case of subcutaneous delivery, the ratio of sensor glucose $C_{\text {Sensor glucose }}$ to blood glucose $C_{B}$ results in:

$$
\mathrm{C}_{\text {Sensor glucose }} / \mathrm{C}_{\mathrm{B}}=\mathrm{F}_{\text {cal }} \mathrm{x} \mathrm{K}_{\text {Sensor }} /\left(\tau_{\text {Sensor }} \mathrm{s}+1\right) \text {. }
$$

It finally follows the ratio of insulin levels in the blood $\mathrm{I}_{\text {Blood }}$ and insulin dosage $\mathrm{I}_{\text {Dose }}$ :

$$
\mathrm{I}_{\text {Blood }} / \mathrm{I}_{\text {Dose }}=\mathrm{K}_{\text {Ins }} /\left[\left(t_{\text {Blood }} \mathrm{s}+1\right) \mathrm{x}\left(\tau_{\mathrm{ISF}} \mathrm{s}+1\right)\right] \text {. }
$$

The formalism aims to predict the expected glucose concentration, thus a complex model of glucose metabolism has to be applied. Different models have been adapted $[23,24]$ including fuzzy logic or neural networks [25,26].

\section{Optical Glucose Measurement}

Some significant progress toward noninvasive optical glucose sensing has come about due to nanomaterials and the unprecedented availability of new fabrication technologies. Optical sensors have a number of advantages, including their capability to be miniaturized for molecule detection schemes, and the ability to function in continuous real time monitoring [27].

Physical methods under consideration are frequently of classical nature: infrared and near-infrared spectroscopy, Raman spectroscopy, and fluorescence spectroscopy. The presence of glucose in optical measurements typically involves a variation in fluorescence intensity or a shift in the wavelength of the light produced by a fluorescent material coupled with a glucose sensitive material.

Optical absorption techniques [28] for quantification of glucose are based on selective absorption of light by the material under study, which is described by the Beer Lambert law, $I=I_{0} \exp (\varepsilon C L)$. Here $I_{0}$ is the intensity of incident optical radiation, $I$ is the transmitted intensity, $\varepsilon$ is the materials extinction coefficient (dependent on the wave length $\lambda$ ), $C$ is the molar concentration, and $L$ is the path length. Measurements are generally reported in absorbance, $A=\log \left(I_{0} / I\right)$, such that the absorbance of several species in the sample material is additive. Glucose sensing using near infrared spectroscopy is plagued by the fact that glucose absorption peaks often yield low signal-to-noise measurements, given that their magnitude is relatively small compared to a large aqueous background spectrum.

Raman spectra are observed when incident light of frequency $v_{0}=c / \lambda_{0}$ is inelastically scattered at frequencies $v_{0 \pm} v_{i}$. The loss (Stokes shift) or gain (anti-Stokes shift) of photon energy, and hence frequency, is due to transitions of the rotational and vibrational energy states within the scattering molecules. The observed shifts $v_{i}$ are independent of the excitation frequency $v_{0}$ and provide specific information about the chemical structure of the sample. The Raman spectrum is independent of the excitation frequency, thus an excitation frequency may be chosen which is appropriate for a particular sample. It is important to note, however, that the intensity of Raman scattered peaks generally falls off with decreasing frequency as the forth power of $v_{0}$. A novel method for glucose detection developed by Stuart, et al. is the adaption of Surface Enhanced Raman Scattering (SERS) for in vivo glucose detection by coating the surface of Ag NPs with decanethiol and mecaptohexanol [29].

Fluorescence-based techniques for glucose sensing, which have demonstrated the best potential, generally fall into two categories: the glucose-oxidase based sensors, and the affinity-binding sensors. Sensors in the first category use the electro-enzymatic oxidation of glucose by glucose-oxidase (GOx) in order to generate an optically detectable glucose-dependent signal.

Physical sensor processes that are built on the interaction of glucose with supplied external energy (electromagnetic fields) for the measurement, although characterized to be non-invasive, have not yet been able to meet the demands of diabetes therapy accuracy and suitability for everyday use.

Presently, devices at the micro- or nanoscale enter the field of diabetes research at its interface with nanotechnology.

\section{Nanotechnology In Glucose Measuring Systems}

When the size of condensed matter is reduced to nanoscale, their physical and chemical properties change drastically. Because of its tiny size, the laws of quantum mechanics govern their electron behavior. Nanotechnology opens up a wealth of new opportunities for the development of new materials, nanostructures, nanoscale electronic devices in general. It involves almost all applications in the diverse medical fields. At the nanoscale, physical, chemical, and biological properties of materials differ in fundamental and valuable ways from the properties of individual atoms and molecules or bulk matter. Most outstanding are quantum effects, as e.g. quantum mechanical tunneling of electrons, electron transport in quantum dots, quantum dot fluorescence, absorption and emission of radiation in a wide frequency range. The surface-to-volume ratio of nanoparticles becomes very large and leads to a number of unexpected physical and chemical effects, such as interfacial phenomena, altered chemical reactivity, charge carrier effects and enhanced optical properties (for example quantum dot fluorescence) [31,33].

Nanoparticles are synonymous with a sub-genre of the wide field of nanotechnology. They include any type of natural or artificial particles whose spatial confinement is less than 100 nanometers. Nanoparticles may contain a few hundred atoms or molecules in one-dimensional array 
(nanowires, quantum wires), two-dimensional (ultrathin layers), or three-dimensional (nano powders, functional supramolecular nanotubes, quantum dots).

Exploitation of nanoparticles in the dermis may allow transdermal monitoring of glucose changes in interstitial fluid. Nanoscale carbon as fullerene, nanotube or graphene exhibits excellent mechanical, electrical and optical properties. Table 1 lists most frequently cited and applied nanoscale structures, each of which with particular properties and applications.

Nanofabrication techniques are known, that generate glucose sensors with very small dimensions. Such small sensors can easily be implanted or be injected as was done with 'glucose detection tattoos' mentioned above [9,32]. Nanotechnology of coated colloids and microcapsules allows precision control over optical, mechanical and catalytic properties to achieve sensitive response. Indeed, there are two steps by which nanoscale building blocks are incorporated in nanosensors: those that improve glucose sensor function, and those that directly measure glucose.

Nanoscale electronics offers new solutions for glucose sensors, providing a high signal-to-noise ratio. One of the best studied nano-materials are carbon nanotubes, both in their single-wall and multiwall structure (single-walled carbon nanotubes, SWCNT, and multi-walled carbon nanotubes, MWCNT). Typically, the diameter of a nanotube is between 0.6 and 6 nanometers, the tube wall reaches a thickness up to 0.3 nanometers. During the production process at very high temperatures, specific substances can be introduced into and onto the nanotubes that react with glucose (for example: glucose oxidase bound to a fluorescent dye). Here, the nanotube works as a light amplifier. The fluorescence signal is proportional to the glucose concentration. It is under study, that such nanotubes are wrapped in a dialysis fiber and transplanted under the skin. The glucose measurement is performed by irradiating the skin area with a laser and measuring the induced fluorescence light as amount of the glucose concentration. From quantum mechanical reasons have thinner nanotubes a larger energy band gap and consequently a stronger energy absorption and fluorescence signal. By use of single-wall nanotubes, enzyme-based optical glucose sensors were reported in [36].

Graphene, a sheet of carbon just one atom thick, shows much promise for use in wearable electronics since it is flexible, soft, conducts electricity very well, and can be transparent.

A graphene-based wireless patch that can detect glucose in sweat has been developed [38]. The device can also deliver metformin - a drug used to treat diabetes - through the skin to reduce high blood glucose levels in diabetic mice.

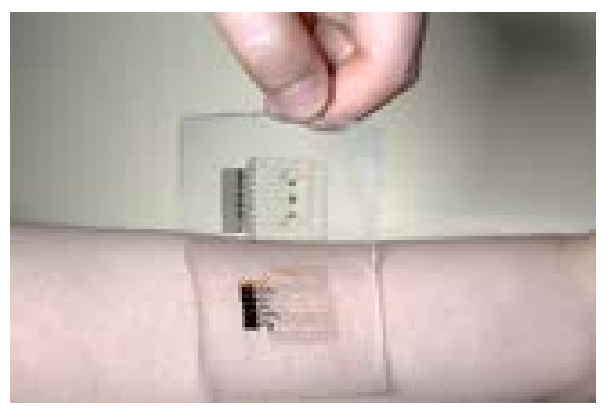

Figure 5. Diabetes batch made of graphene (after [38])
The implantation of reversible optical sensors has led to the concept of a 'smart tattoo' that continuously measures the blood glucose level by modulating the tattoo's optical color in response to glucose concentration [9]. Carbon nanotubes exhibit properties, which make them ideal for fluorescent biosensing, such as emission at a near-infrared wavelengths, which is a wavelength at which skin is particularly transparent. Owing to its small size, high electrochemical activity, excellent physical properties, low density and biocompatibility, the CNT fibre has huge potential for implantable applications for continuous monitoring of clinically relevant analytes, including glucose.

He and co-workers [30] reported a highly sensitive glucose sensor made by immobilizing $\mathrm{GOx}$ on $\mathrm{Ag} / \mathrm{Au}$ nanoshells via poly(L-histidine).

Several optical sensor approaches utilizing metal nanoparticles have been developed. As one example, a novel photoluminescent glucose nanosensor was presented by Shao-wei Gao et al. [12], characterized by coupling glucose oxidase (GOx) with poly-L-lysine coated oxygen nanosensors via a glutaraldehyde-mediated Schiff-base reaction. The proposed glucose nanosensor had a quick response time from less than 2 to 4 minutes. Results are shown in Figure 6. A fourfold increase of the probe peak at about $\lambda=660 \mathrm{~nm}$ during a time laps of three minutes is observed.

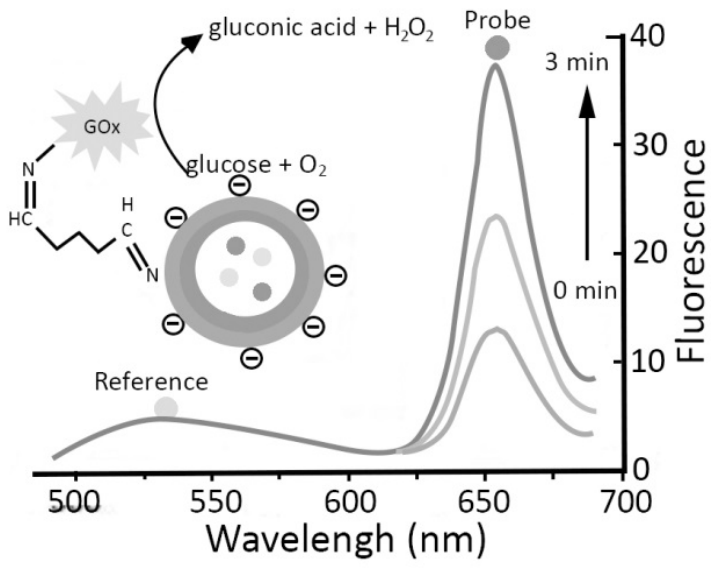

Figure 6. Photoluminescent enzymatic nanosensor for glucose sensing by use of oxygen sensitized radiometric fluorescence nanoparticles (NPs) and glucose oxidase (GOx), (after [12])

Micro- and nanoelectronic technologies offer the possibility of a cost-effective mass production. As the costs of such sensors depend on their widespread usage, diabetes therapy might be revolutionized if low-cost glucose sensors based on nanotechnology become available.

Bundles of double-walled carbon nanotubes, 28 micrometers in diameter, were designed for electrochemical biosensor applications, which efficiently worked as an enzymatic glucose biosensor [37]. The bundles of CNTs were concentrically compacted into multiple layers, forming a nano-porous network structure. The electrode end tip of the CNT fiber was freeze-fractured to obtain a unique brush-like nano-structure resembling a scale-down electrical 'flex', where glucose oxidase (GOx) enzyme was immobilized using glutaraldehyde crosslinking in the presence of bovine serum albumin. Superior efficiency of CNT fiber for glucose biosensing was demonstrated compared to a traditional Pt-Ir sensor. 
Table 1. Nanomaterials in different geometrical structures and dimensions, all of which imply specific physical and chemical properties, and widespread applications

\begin{tabular}{|c|c|c|}
\hline NANOMATERIALS & CHARACTERISTICS & STRUCTURE \\
\hline $\begin{array}{l}\text { Nanoparticle } \\
\text { Quantum dot } \\
\text { Fullerene } \\
\text { Nanocluster } \\
\text { Colloid } \\
\text { Nanocrystal } \\
\text { some Virus, proteins }\end{array}$ & $\begin{array}{l}\text { Confinement of electrons in three dimensions; } \\
\text { Spatial confinement is less than } 100 \mathrm{~nm} \text { in any of } \\
\text { direction } \mathrm{x}, \mathrm{y}, \mathrm{z}\end{array}$ & $\begin{array}{l}\text { ZERO-DIMENSIONAL (OD) } \\
\text { When the dimensions in } x, y, z \text { direction are below the } \\
\text { threshold of } 100 \mathrm{~nm} \text {, the nanostructure is referred to as } \\
O D \text {. }\end{array}$ \\
\hline $\begin{array}{l}\text { Nanotube } \\
\text { Nanocable } \\
\text { Nanofiber } \\
\text { Nanofilament } \\
\text { Nanorod } \\
\text { Nanoribbon, Nanobelt } \\
\text { Nanopowder } \\
\text { Nanopore } \\
\text { Linear chain structure } \\
\text { Quantum wire } \\
\end{array}$ & $\begin{array}{l}\text { Confinement of electrons in two dimension; } \\
\text { Geometrical structure extension less than } 100 \mathrm{~nm} \text { in } \mathrm{x}, \mathrm{y} \text {. } \\
\text { No restriction in direction } \mathrm{z}\end{array}$ & $\begin{array}{l}\text { ONE-DIMENSIONAL (1D) } \\
\text { When the dimension both in the } x \text { and } y \text { direction is below } \\
\text { the critical value of } 100 \mathrm{~nm} \text { ) the nanostructures are } \\
\text { defined as } 1 D\end{array}$ \\
\hline $\begin{array}{l}\text { Monolayer } \\
\text { Graphene } \\
\text { Nanocoating } \\
\text { Nanoplatelet } \\
\text { Thin film } \\
\text { Quantum well } \\
\text { Multilayer } \\
\text { Supergitter }\end{array}$ & $\begin{array}{l}\text { Confinement of electrons in } \\
\text { one dimension; } \\
\text { Geometrical structure extension less than } 100 \mathrm{~nm} \text { in x. No } \\
\text { restriction in direction y, z. }\end{array}$ & $\begin{array}{l}\text { TWO-DIMENSIONAL (2D) } \\
\text { The family of } 2 D \text { nanosystems encompasses all those } \\
\text { systems that exhibit two dimensions exceeding the third } \\
\text { one }\end{array}$ \\
\hline $\begin{array}{l}\text { Nanosphere } \\
\text { Nanoflower } \\
\text { Nanoshell } \\
\text { Polycrystals w/nanosize } \\
\text { grains } \\
\text { Superatom } \\
\text { Bulk-(semi)conductor }\end{array}$ & $\begin{array}{l}\text { No confinement of electrons in any dimension; } \\
\text { No geometrical structure restrictions }\end{array}$ & $\begin{array}{l}\text { THREE-DIMENSIONAL (3D) } \\
\text { Objects having either an overall size in the non- } \\
\text { nanometric range, but displaying nanometric features } \\
\text { (such as nanosized confinement spaces) or resulting from } \\
\text { the periodic arrangement and assembly of nanosized } \\
\text { building blocks, can be classified as } 3 D \text { nanosystems }\end{array}$ \\
\hline
\end{tabular}
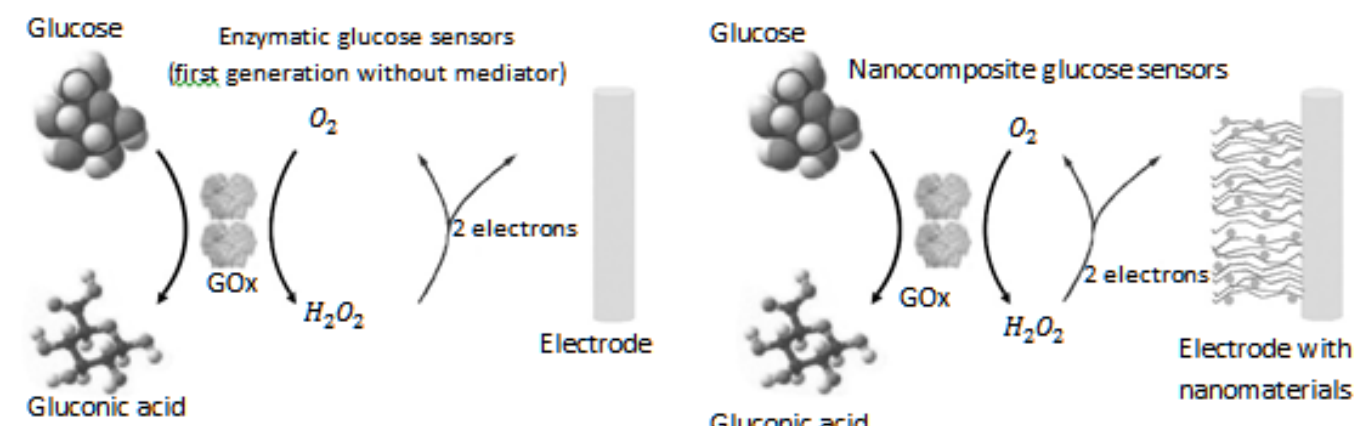

Gluconic acid

Figure 7. Nanostructured materials used in glucose sensors. Currently applied electrochemical glucose sensors (left) use glucose oxidase (GOx) to generate an electrochemical signal. This signal is transferred through $\mathrm{O}_{2}$ reduction into $\mathrm{H}_{2} \mathrm{O}_{2}$ (or some other chemical mediator). Nanomaterials, as nanotubes or nanocomposites, are incorporated into such sensors (right) aiming to increase the surface area, improve catalytic efficacy, modify operating parameters, and improve the electron transfer from enzyme to electrode (adapted from [2])

The implementation of nanostructured materials in glucose sensors as compared to currently used GOx sensors of the first generation is shown in Figure 7. Similar to ordinary glucose sensors, based on GOx, the electron transfer between the enzyme and the electrode can be enhanced by use of an electrochemical mediator.

Improvement in sensor performance is made possible by the combination of CNTs with various nanoparticles, as e.g. noble metals (silver, gold, platinum) or silica, as shown in Figure 7, by which the catalytic activity and in consequence the sensitivity of measurement is enhanced.

\section{Conclusions}

Intense research in the field of diabetes is driven by the high and continuously growing number of diabetes cases, particularly of type 2 worldwide. Different approaches to 
improve conventional methods of glucose measuring and control have yet too little contributed to overcome painful daily finger pricking. Current efforts in the creation of an artificial pancreas make use of opportunities generated by the new field of nanotechnology.

Nanomaterials are unique in many of their physical and chemical properties, and make it suitable for applications in several key technologies, such as down scaled sensors and imaging devices, nanoelectronics and nanophotonics, energy conversion and nanobiomedicine. The connection of the advanced medicine to micro- and nanoelctronic technologies offers the prospect of new approaches and the possibility of cost-effective mass fabrication of devices. As the cost of sensor production determines its distribution, the treatment of diabetes might be transformed, particularly in terms of the control of an artificial pancreas. The application of nanotechnology resources and processes not only supports the current effort in the creation of an artificial pancreas, it also provides a high number of new ways and methods. These relate in particular to long-time stable and reliable measuring glucose sensors, which can be incorporated in blood vessels. For sensors in which the measurement of glucose is based on enzyme-catalyzed biochemical conversion of glucose, nanotechnology provides advantages that are particularly justified in addition to the device miniaturization. These new opportunities will affect and change many aspects of life.

\section{Acknowledgements}

This work was funded in part by CONACYT-SENER through project CEMIE 250014 Cluster Biodiesel Avanzado.

\section{Statement of Competing Interests}

The authors have no competing interests.

\section{References}

[1] Etheridge, M.L., S.A. Cambell, A.G. Erdmann, C.L. Haynes, S.M. Wol, J. McCullough, The big picture on nanomedicine: The state of investigational and approved nanomedicine products, Nanomedicine: Nanotechnology, Biology, and Medicine 9, 1-14 (2013).

[2] Cash, K. J. , H. A. Clark, "Nanosensors and nanomaterials for monitoring glucose in diabetes", Trends in Molecular Medicine, 16, 584-593 (2010)."Diagnosis and Classification of Diabetes Mellitus”, Diabetes Care 2004, Suppl. 1, 27:s5-s10, American Diabetes Assoc. (2004); IDF Diabetes Atlas, 7. Edition 2015, International Diabetes Federation, (2015).

[4] Agrawal, S., R. Prajapati, "Nanosensors and their pharmazeutical applications: a review”, MS ID: IJPSN-11-20-11-AGRAWAL, Int. J. Pharm. Sci. Nanotech. 4, 4 (2012).

[5] Lerner, M. B., N. Kybert, R. Mendoza, R. Villechenon, M.l A. Bonilla Lopez, A.T. C. Johnson, "Scalable Non-Invasive Glucose Sensor Based on Boronic Acid Functionalized Carbon Nanotube Transistors”, arXiv:1304.7253 [cond-mat.mtrl-sci].

[6] Nyitray, C. E., R. Chang, G Faleo, K. D. Lance, D.A. Bernards, Q. Tang, and T. A. Desai, "Polycaprolactone Thin-Film Micro-and Nanoporous Cell-Encapsulation Devices”, ACS Nano, 9, 56755682 (2015)

[7] Mahendran, V., J. Philip, "Non-enzymatic glucose detection using magnetic nanoemulsions”, Appl. Phys. Lett. 105, 123110 (2016).
[8] Zhang, B., R. B. Kumar, H. Dai, B. J. Feldman, "A plasmonic chip for biomarker discovery and diagnosis of type 1 diabetes", Nature Medicine 20, 948-953 (2014).

[9] Heo, Y.J., S. Takeuchi, "Towards smart tattoos: implantable biosensors for continuous glucose monitoring”, Adv Healthc Mater. 2, 43-56 (2013).

[10] Zhang, Q., S. Yang, J. Zhang, L. Zhang, P. Kang, J. Li, J. Xu, H. Zhou, X. M. Song, "Fabrication of an electrochemical platform based on the self-assembly of grapheneoxide-multiwall carbon nanotube nanocomposites and horseradish peroxidase: direct electrochemistry and electrocatalysis”, Nanotechnology, 22, 49 (2011).

[11] Balaconis, M. K., Y. Luo, H. A. Clark, "Glucose-sensitive nanofiber scaffolds with an improved sensing design for physiological conditions”, Analyst 140, 716-723 (2015).

[12] Gao, S. W., H. S. Peng, X. Xui Wang, F. T. You, F. Teng, H. Xia Wang, "Preparation of photoluminescent enzymatic nanosensors for glucose sensing", Sensors and Actuators B, 222, 638-644 (2016).

[13] El-Khatib, F.H., S.J. Russell, D.M. Nathan, R.G. Sutherlin, E.R. Damiano, "A bihormonal closed-loop artificial pancreas for type 1 diabetes”, Sci. Transl. Med. 2:27ra27 (2010)

[14] Shahidadpury, V., A. Hirani, Y. Pathak, "Stem cell nano drug delivery applications to treat diabetes", Europ. Pharm. Review May 2016

[15] Choudhary, P., J. Shin, Y. Wang, M.L. Evans, P.J. Hammond, D. Kerr, J.A.M. Shaw, J.C. Pickup, S.A. Amiel, "Insulin Pump Therapy with automated insulin suspension in response to hypoglycemia - Reduction in nocturnal hypoglycemia in those at greatest risk”. Diabetes Care 34, 2023-2025 (2011).

[16] Danne, T., O. Kordonouri, K. Remus, S. Bläsig, M. Holder, T. Wadien, H. Haberland, S. Golembowski, S. Zierow, R. Hartmann, A. Thomas, "Prevention of hypoglycaemia by using low glucose suspend function in sensor-augmented pump therapy", Diabetes Technology \& Therapeutics 13,1129-113 (2011).

[17] Ly, T.T., J.A. Nicholas, A, Retterath, E.M. Lim, E.A. Davis, T.W. Jones, "Effect of Sensor-Augmented Insulin Pump Therapy and Automated Insulin Suspension vs Standard Insulin Pump Therapy in Patients with Type 1 Diabetes. A Randomized Clinical Trial”, JAMA 310, 1240-1247 (2013).

[18] Danne, T., C. Tsioli, O. Kordonouri, S. Blaesig, K. Remus, A. Roy, B. Keenan, S.W. Lee, F.R. Kaufman, "Predictive Low Glucose Management with sensor augmented CSII in response to exercise" Diabetes Technology and Therapeutics 16 (2014).

[19] Shan, C., H. Yang, D. Han, Q. Zhang, A. Ivaska, L. Niu. "Graphene/AuNPs/chitosan nanocomposites film for glucose biosensing”, Biosensors and Bioelectronics. 25, 1070-74 (2010).

[20] Zeng, X., X. Li, L. Xing, X. Liu, S. Luo, W. Wei, B. Kong B, Y. $\mathrm{Li}$, "Electrodeposition of chitosan-ionic liquid-glucose oxidase biocomposite onto nano-gold electrode for amperometric glucose sensing”. Biosensors and Bioelectronics, 24, 2898-2903 (2009).

[21] Weitai Wu, Ting Zhou, Jing Shen and Shuiqin Zhou, "Optical detection of glucose by CdS quantum dots immobilized in smart microgels", Chem. Commun., 0, 4390-4392 (2009).

[22] El-Khatib, F.H., S.J. Russell, D.M. Nathan, R.G. Sutherlin, E.R. Damiano, "A bihormonal closed-loop artificial pancreas for type 1 diabetes”, Sci Transl Med 22, 27 (2010).

[23] Thomas, A., I. Zamora-Ginez, A. Ramírez, "Páncreas endocrino artificial - el anhelo de los pacientes con diabetes", J. Nanociencias et Moletronica, 13, 2 (2015).

[24] Dassau, E., F.M. Cameron, H. Lee, B.W. Bequette, F.J. Doyle, G. Niemeyer, P. Chase, B.A. Buckingham, "Real-time Hypoglycemia Prediction Using Continuous Glucose Monitoring (CGM), A Safety Net to the Artificial Pancreas”, Diabetes 57, A13 (2008).

[25] Atlas, E., R. Nimri, S. Miller, E.A. Grunberg, M. Phillip, "MD logic artificial pancreas system: a pilot study in adults with type 1 diabetes”. Diabetes Care 33, 1072-1076 (2010).

[26] Perez-Gandia, C, A. Facchinetti, G. Sparacino, C. Cobelli, E.J. Gomez, M. Rigla, A. de Leiva, M.E. Hernando, “Artificial Neural Network Algorithm for Online Glucose Prediction from Continuous Glucose Monitoring”, Diabetes Technol. Ther. 12, 81-88 (2010).

[27] Yetisen, A.K., Y. Montelongo, F. da Cruz-Vasconcellos, J.L. Martinez-Hurtado, S. Neupane, H. Butt, M.M. Qasim, J. Blyth, K. Burling, J.B. Carmody, "Reusable, Robust, and Accurate LaserGenerated Photonic Nanosensor", Nano Letters 14, 3587-93 (2014). 
[28] McNichols, R. J., G. L. Coté "Optical glucose sensing in biological fluids: an overview”, J. Biomed. Optics 5, 5-16 (2000).

[29] Stuart, D.A., J.M. Yuen, N. Shah, O. Lyandres, C.R. Yonzon, M.R. Glucksberg, J.T. Walsh, R.P. Van Duyne, "In Vivo Glucose Measurement by Surface-Enhanced Raman Spectroscopy", Analytical Chemistry 78, 7211-7215 (2006).

[30] He, H., X. Xu, H. Wu, Y. Jin, "Enzymatic Plasmonic Engineering of Ag/Au Bimetallic Nanoshells and Their Use for Sensitive Optical Glucose Sensing”. Adv. Mater., 24, 1736-1740 (2012).

[31] Allhoff, F., P.Lin, D.Moore, "The basics of nanotechnology" .In: What Is Nanotechnology and Why Does It Matter? From Science to Ethics. New York, NY: John Wiley; 2010: 1-19.

[32] Brown, J.Q., M.J. McShane, "Modeling of spherical fluorescent glucose microsensor systems: design of enzymatic smart tattoos", Biosens Bioelectron. 21, 1760-1769 (2006).

[33] Thomas, A., E. Torres, A. Ramírez, A. Zehe, "Las nanopartículasNanomateriales de tantas aplicaciones asombrosas en nanomedicina y nanotecnología biomédica”, Internet Electron. J Nanocs Moletrón. 13, 2315-2326 (2015).
[34] Radushkewitsch, L.K., V.M. Lukjanowitsch, "O struktura ugleroda, obrazujucegosja pri termitscheskom razlozenii okisi uglerodana zeleznom kontakte”. J. Fis. Chim. 26, 88-95 (1952).

[35] Iijima, S., T. Ichihashi, "Single shell carbon nanotubes of $1 \mathrm{~nm}$ diameter”. Nature 363, 603-605 (1993).

[36] Barone, P.W., M.S. Strano, "Single walled carbon nanotubes as reporters for the optical detection of glucose", J. Diabetes Sci. Technol. 3, 242-252 (2009).

[37] Zhu, Z., W. Song, K. Burugapalli, F. Moussy, Y.L. Li, X.H. Zhong, "Nano-yarn carbon nanotube fiber based enzymatic glucose biosensor", Nanotechnology 21, 165501 (2010).

[38] Hyunjae, ] L. T.K. Choi, Y.B. Lee, H. R. Cho, R. Ghaffari, L. Wang, H.J. Choi, T. D. Chung, N. Lu, T. Hyeon, S.H. Choi, D.H. Kim, "A graphene-based electrochemical device with thermoresponsive microneedles for diabetes monitoring and therapy”, Nature Nanotechnology 11, 566-572 (2016). 